\title{
Promover os talentos para reduzir a pobreza
}

\author{
ENRICO N OVARA
}

\section{Introdução}

A DIM EN SÃo do fenômeno da pobreza urbana no Brasil é de conhecimento público, seja porque nos últimos anos os meios de comunicação colocaram em evidência os dados desse fenômeno, seja porque convivemos cotidianamente com a pobreza. Assim, sabemos que $30 \%$ da população vive abaixo da linha de pobreza.

N o Brasil, a pobreza assume características peculiares, distinguindo-se de outros países que enfrentam as mesmas necessidades de criar uma condição de rápido crescimento socioeconômico para melhorar os padrões de vida da sua população.

D e fato: “o Brasil não é um país pobre, mas um país injusto e desigual, com muitos pobres. Os elevados níveis de pobreza resultam, primordialmente, da intensa desigual dade na distribuição da renda e nas oportunidades de inclusão econômica e social" (Barros et al., 2000 (b), p. 11).

A desigualdade das condições de vida é o principal obstáculo a ser removido para garantir um crescimento sustentável, assim, o principal objetivo a ser alcançado pelas políticas públicas é a sua redução.

D escrever corretamente o problema da pobreza, isto é, tratar de maneira mais adequada possível a realidade, representa, portanto, o passo decisivo para definir os conteúdos dos programas e os mais apropriados instrumentos para nortear a ação.

U ma investigação séria sobre qualquer acontecimento ou objeto que se apresenta à nossa atenção precisa de "realismo".

Com isto, tenho a intenção de referir-me à urgência de não privilegiar um esquema que já tenhamos em mente em detrimento de uma observação global, apaixonada e insistente do fato, do acontecimento real (Giussani, 2000, p. 19).

U m dos mais jovens cientistas que recebeu o Prêmio N obel de M edicina, Alexis Carrel, afirma no seu livro R eflexões sobre a conduta da vida que "pouca observação e muito raciocínio conduzem ao erro. M uita observação e pouco raciocínio conduzem à verdade" (Carrel apud Giussani, 2000, p. 20). Carrel parece realmente nos dizer que somente uma paixão pela realidade concreta, com as formas com que ela se apresenta aos nossos olhos, permite vencer uma 
leitura dos fatos, influenciada por um juízo anterior, e permite superar, na ação, as divisões ideológicas. Só assim o método é definido pelo objeto e não imaginado, de maneira abstrata, pelo sujeito que realiza a ação ${ }^{1}$. Só assim é possível definir instrumentos ad equados à realidade que estamos enfrentando.

N este sentido, a presente contribuição quer, em primeiro lugar, apresentar as formas mais conhecidas, hoje no Brasil, de perceber e analisar o fenômeno da pobreza e as suas conseqüências operativas; percorrer as modalidades históricas por meio das quais o problema da pobreza urbana foi abordado nos últimos vinte anos, impulsionadas pela objetiva necessidade de melhorar as condições de vida dos moradores das favelas; e sugerir, enfim, uma modalidade de intervenção, que se diferenciando das experiências anteriores, coloque como centro do desenvolvimento a pessoa com as suas potencialidades expressas e latentes.

\section{E ntre renda e exclusão: interpretações difundidas do fenômeno da pobreza}

N os últimos anos, o Instituto de Pesquisa E conômica Aplicada do M inistério do Planejamento dedicou particular atenção ao estudo eao dimensionamento da pobreza no Brasil. A pobreza é enfrentada na sua dimensão de renda insuficiente: "Existe pobreza somente à medida que existem famílias que vivem com uma renda familiar per capita inferior ao nível mínimo para satisfazer as próprias necessidades elementares (Barros et al., 2000 (a), pp. 22-23)" 2 .

Portanto, segundo esta primeira afirmação, o pobre éaqueleque possui uma renda que não Ihe permiteadquirir uma quantidade debenssuficiente para satisfazer as suas necessidades primárias É a definição clássica e bem conhecida da poverty line, que acaba exigindo que se faça um cálculo de valores diferentes de "pobreza" em função do contexto econômico/ regional, bem como do diferente valor de aquisição de bens al imentícios e de primeira necessidade. Sem entrar no mérito desta modalidade de cálculo, aceita-se, de modo geral, o valor médio e significativo de um dólar ao dia per capita. A definição de "linha de indigência" depende de uma variação de cálculo de renda que impõe uma meta de pura sobrevivência. O s números sobre a pobreza no Brasil neste início de novo século são bem conhecidos: um terço da população vive abaixo da linha de pobreza, sendo que um pouco menos da metade, em condições miseráveis ${ }^{3}$. M as a linha de pobreza não descreve de maneira a exaurir a real dimensão econômica do problema.

O tamanho da pobreza é diretamente proporcional ao número de pessoas que vivem em famílias para as quais a renda per capita encontra-se abaixo da linha de pobreza e à distância da renda per capita de qualquer família pobre em relação à linha de pobreza (Barros et al., 2000 (a), p. 23).

D efine-se, assim, o "hiato de pobreza" , isto é, o valor econômico que aquela família deve receber para elevar a sua renda acima da linha de pobreza. É possível, deste modo, calcular o débito social do país. Feitas as contas, usando o coeficien- 
te de Gini ou a razão entre a renda do quintil mais rico da população e o quintil mais pobre, o Brasil acaba sendo um dos países que pior distribui a própria renda.

A definição de pobreza por meio dos poucos indicadores econômicos, rapidamente apresentada, permite identificar e localizar facilmente o grupo vulnerável, mas não consente descrever as causas e características do fenômeno, a não ser aquela que diz respeito à falta de uma renda adequada. Como conseqüência disso, as políticas de redistribuição de renda, diretas e necessárias, propõem resultados mais ligados ao âmbito da emergência do que à tentativa de favorecer 0 desenvolvimento da pessoa e da comunidade.

Para se evitar que os beneficiários dos programas de renda mínima retornem à sua condição de pobreza anterior, são necessárias a articulação e a integração de outras ações sociais que tenham como objetivo a conquista da autonomia (L avinas em Aguiar e Araújo, 2002, p. 14).

As políticas de redistribuição não podem e nem devem ficar à margem das políticas sociais, mas devem, evidentemente, ser integradas com a real possibilidade de crescimento da pessoa.

A renda mínima, para se tornar poderoso instrumento de combate à pobreza e à desigualdade, deveria estar associada a outras políticas sociais. U ma família pobre que tenha uma renda mínima, mas que more em um bairro sem saneamento básico, que tenha filhos sem acesso ao ensino fundamental, não tenha saúde adequada, não participe de forma efetiva na esfera da política e que esteja submetida à arbitrariedade das açõ es policiais continua em um processo de pobreza, desigualdade social e até mesmo exclusão (Aguiar e Araújo, 2002, p. 32).

U ma segunda forma conhecida de interpretar a realidade da pobreza é aquela que tenta definir a "qualidade de vida" ou de "bem-estar" da população ampliando o leque dos fatores que contribuem para determinar aquelas situações, indo além do fator econômico.

Portanto, outras dimensões elementares, tais como a saúde, educação, emprego ou outras mais complexas, como segurança e cultura, podem definir uma melhor ou pior qualidade de vida. N os últimos anos foram elaborados vários indicadores de "bem-estar". Entre os mais usados no Brasil podemos citar apenas dois: o Í ndice de D esenvolvimento H umano (ID H ), colocado justamente nos últimos dez anos pela U nited N ationsD evel opment Programme(U N D P) e divulgado em âmbito mundial para permitir uma comparação entre as nações, e o Í ndice de Vulnerabilidade Social (IVS) que, embora tendo que ser adaptado à situação local, foi elaborado em várias capitais do Brasil. Ambos são representados por um indicador misto. 0 primeiro é composto de três variáveis: a longevidade, o nível de instrução e o nível econômico de vida, medidos respectivamente pela expectativa de vida a contar do nascimento, pelo percentual de analfabetismo da população em idade adulta, da taxa de escolaridade e, enfim, da renda média per capita. 0 indicador final, que varia entre zero (ausência de desenvolvimento) 
e um (desenvolvimento completo), pode classificar o grupo populacional que éo objeto do estudo nas diferentes categorias de desenvolvimento (alto, médio e baixo). M esmo segundo esta análise, o Brasil se mantém como um país desequilibrado. D e fato, é a única potência econômica inserida no compacto grupo de nações com desenvolvimento médio ${ }^{4}$. U m exemplo de aplicação do IDH nas políticas de redução da pobreza no Brasil é a concentração de programas setoriais da "C omunidade Solidária" direto em grupos homogêneos (redução do analfabetismo, Bolsa-E scola, redução da mortalidade infantil, incentivo à formação profissional) nos estados com ID H inferior à média nacional, isto é, nos catorze Estados brasileiros considerados de baixo desenvolvimento humano (valor inferior a 0,5 ).

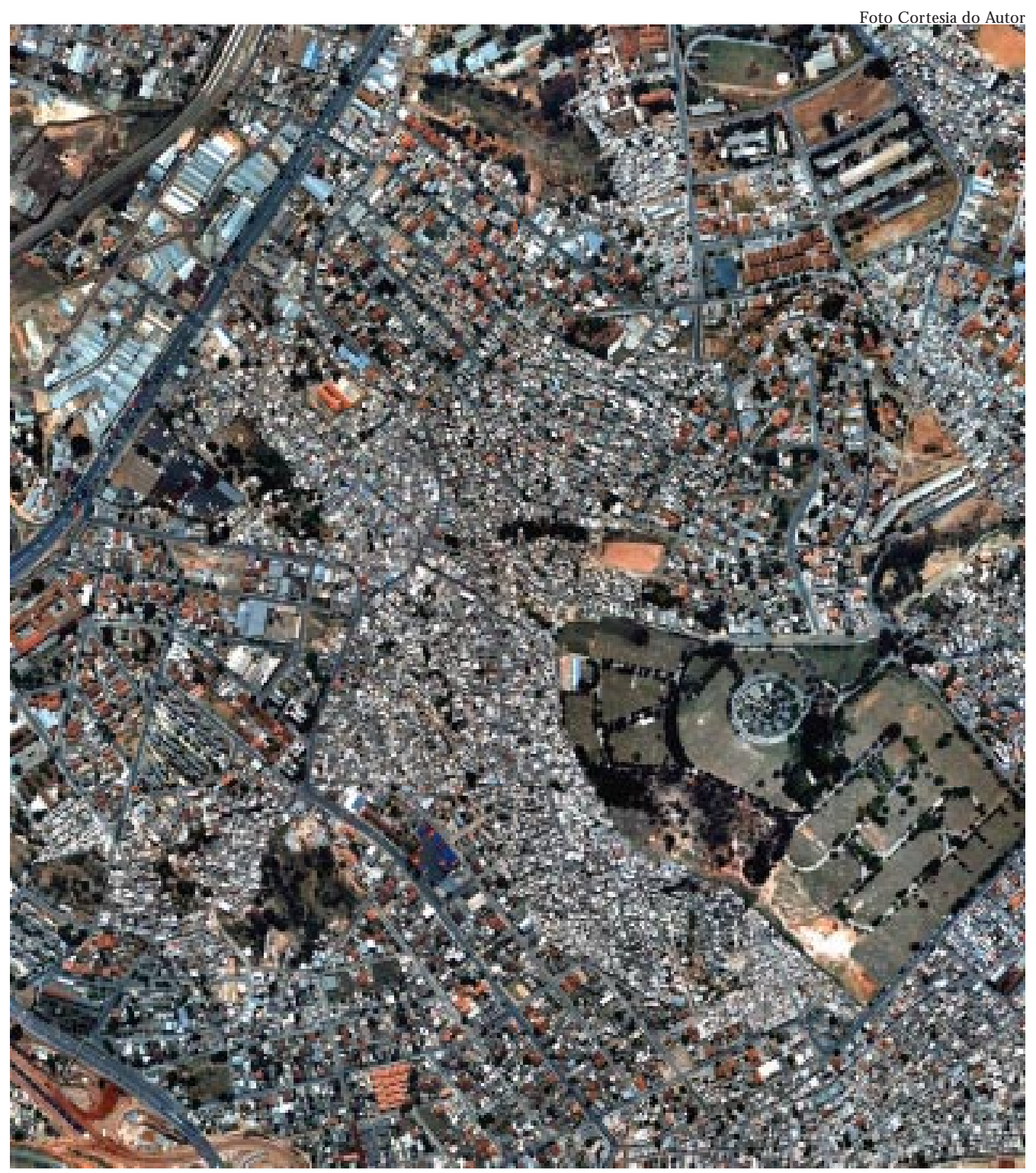

A glomerado C abana: contrastesurbanísti cosna ci dade de B elo H orizonte( M G). 

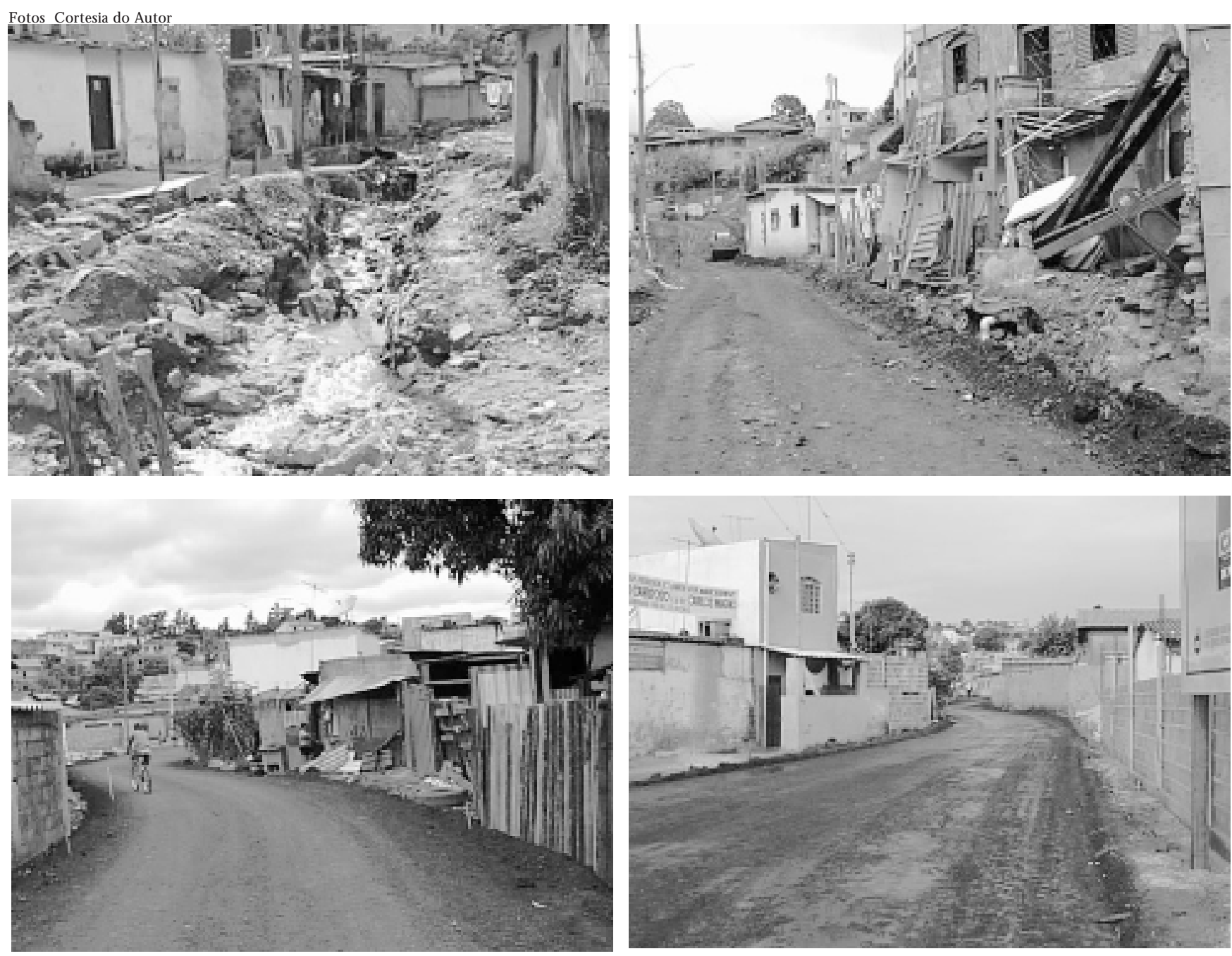

Processos de urbanização de favelasa poiados pela AVSI na região deC ontagem (Belo H orizonte-M G) .

O Índice de Vulnerabilidade Social (IVS) ${ }^{5}$ nasce da combinação de mais de vinte variáveis que tendem a medir um leque mais amplo de dimensões: ambiental, cultural, econômica, jurídica e de segurança. Também nestes casos, o índice serve para definir os grupos majoritariamente vulneráveis em um determinado território e serve igual mente para garantir a concentração de programas locais e nacionais como no caso do Programa BH -Cidadania, em Belo H orizonte ${ }^{6}$.

0 exemplo mais exaustivo da medida da pobreza, através de indicadores de exclusão, está representado no trabalho realizado por M. Pochmann eR. Amorim, publicado recentemente com o título: A tlas de exclusão social no Brasil. Esse documento apresenta a classificação da Exclusão Social de todos os municípios brasileiros, por meio de um calculo baseado em dados indiretos fornecidos pelo IBGE.

Assim, embora sejam diversas as formas de identificar os níveis aceitáveis de qualidade de vida, quase sempre se define o pobre como alguém que não possui acesso estável a uma série de serviços que uma comunidade produziu em um 
determinado contexto regional. Portanto, o pobre é aquele que está excluído da possi bilidade de usufruir as conqui istas e dos progressos soci oeconômi cos que a sociedadeacumulou à medida quefoi searticulando.

O pobre, dessa forma, vive em uma situação instável, de extrema vulnerabilidade, no contexto social. Vulnerabilidade é, de fato, um conceito mais amplo que a simples carência ou necessidade; significa viver sem defesas, em uma situação de insegurança, exposto a riscos, ao desconforto e à tensão.

Certamente, esta segunda abordagem do tema reconhece um ponto de partida objetivo: a pobreza é um fenômeno multidimensional e dinâmico, e introduz, por isso, um assunto muito mais amplo: aquele dos serviços de utilidade pública' . Q uestões como: qual é a natureza dos serviços no profit de utilidade pública? Como melhorar a qualidade e a eficiência? Como avaliá-las?? Q uais devem ser os relacionamentos entre política pública e a ação dos serviços privados no profit? devem ser enfrentadas para garantir um real processo de inclusão. Vale a pena lembrar pelo menos dois elementos de interesse para a nossa discussão:

- Para definir a qualidade é necessário definir de maneira inequívoca o padrão aceitável de um serviço, de modo tal que as iniciativas comunitárias da sociedade civil possam medir a qualidade do próprio serviço e melhorar as prestações dos mesmos.

- U ma forma concreta de garantir o acesso aos serviços é aquela de financiar e promover serviços de utilidade pública voltados à população mais vulnerável ou de criar também as condições econômicas, para que os mais pobres possam efetivamente ter acessibilidade aos serviços existentes.

O Programa Bolsa-E scola, por exemplo, associa elementos de redistribuição de renda à garantia de acesso aos serviços.

A Bolsa Escola é superior aos programas de renda mínima porque integra de forma estratégica a complementação de renda ao acesso universal à educação, bem como combate à evasão escolar. O s beneficiários são crianças de famílias muito pobres, que, sem a bolsa mensal, evadiriam do sistema escolar, mantendo a mesma baixa escolaridade dos pais e, conseqüentemente, no futuro, ingressariam no mercado de trabalho, na melhor das hipóteses, nas mesmas condições da maioria de suas famílias. A lógica é elevar o grau de escolaridade das crianças para aumentar e mesmo equilibrar as oportunidades. A Bolsa-Escola consiste em repassar um recurso mensal para as famílias excluídas desde que todos os filhos em idade escolar freqüentem pelo menos $90 \%$ dos dias letivos (Aguiar e Araújo, 2002, pp. 34-35).

Ao contrário, em um outro programa, chamado "A poio à Distância", a AVSI coloca em contato, através de depósito de uma conta mensal, uma família com uma criança ou adolescente que vive em situação de risco social para garantir o seu percurso educativo. 0 resultado das quatro mil adesões, no Brasil, é destinado trimestralmente a trinta centros educativos no profit que atendem, em várias cidades brasileiras, as crianças que recebem este sustento. O s fundos são 
transformados em benefícios diretos no âmbito da educação. Escolhe-se, deste modo, reforçar os serviços de utilidade pública, os quais são dirigidos unicamente às comunidades vulneráveis.

Em ambos os casos, vê-se como o problema da qualidade dos serviços, além do acesso a eles, torna-se um elemento indispensável para reduzir efetivamente as condições de vulnerabilidade das pessoas, como veremos no caso do Programa Ribeira Azul apresentado no final deste documento.

\section{A marca da pobreza urbana: uma cidade fragmentada}

Até agora nos limitamos a examinar, de fora, a situação de vida dos mais pobres procurando identificar as dimensões e as características do fenômeno. Ambos os modelos, no entanto, não colocam em evidência um elemento fundamental da pobreza: a sua local ização na cidade e a tipologia dos espaços ocupados pelas famílias pobres. Temos que evitar o risco de conhecer os fenômenos só pelos dados estatísticos. U ma forma realista de enfrentar o problema impõe, de fato, um envolvimento com o objeto que se pretende conhecer.

Para realizar-se programas de redução da pobreza temos que adentrar concretamente nas favelas de nossas cidades, entender como e porque nasceram, identificar as causas que ao longo dos anos caracterizaram a impotência que 0 poder público demonstrou em responder à aceleração do fenômeno, descobrir as raízes que geraram nos pró prios habitantes as primeiras tentativas de resposta, descrever o desenvolvimento dessas tentativas em programas de urbanização e entender como esses satisfizeram a necessidade e o desejo de uma vida melhor.

D e fato, a configuração espacial, isto é tipológica e morfológica da cidade brasileira, é o principal e mais nítido retrato das formas, por meio das quais se apresenta o fenômeno da pobreza. A cidade carrega consigo as feridas causadas pela desigual distribuição das riquezas e pela exclusão social; da mesma forma, hoje, se tornam visivelmente experimentáveis as primeiras tentativas de resposta.

$\mathrm{N}$ ão podemos, porém, definir estratégias eficazes de redução da pobreza sem considerar o contexto territorial e os aspectos morfológicos que o caracterizam, da mesma forma não podemos abordar o fenômeno da urbanização das favelas, que a partir dos anos de 1980 tornou-se um tema recorrente nas políticas urbanas das principais cidades, sem aprofundar em termos globais o problema da pobreza.

Estamos acostumados a representar a cidade em duas partes: a cidade formal e a parte informal, isto é, aquela que não se desenvolveu conforme as regras previstas pelo planejamento urbano e, portanto, sem infra-estrutura e serviços básicos.

A arquitetura silenciosa aparece sem alarde, como que de surpresa; quando menos se espera, lá está, consolidada. Pode ser entendida como arquitetura espontânea, surgida diretamente do envolvimento da população com a produção de seus espaços de moradia, de trabalho, de lazer, entre outros. [...] 

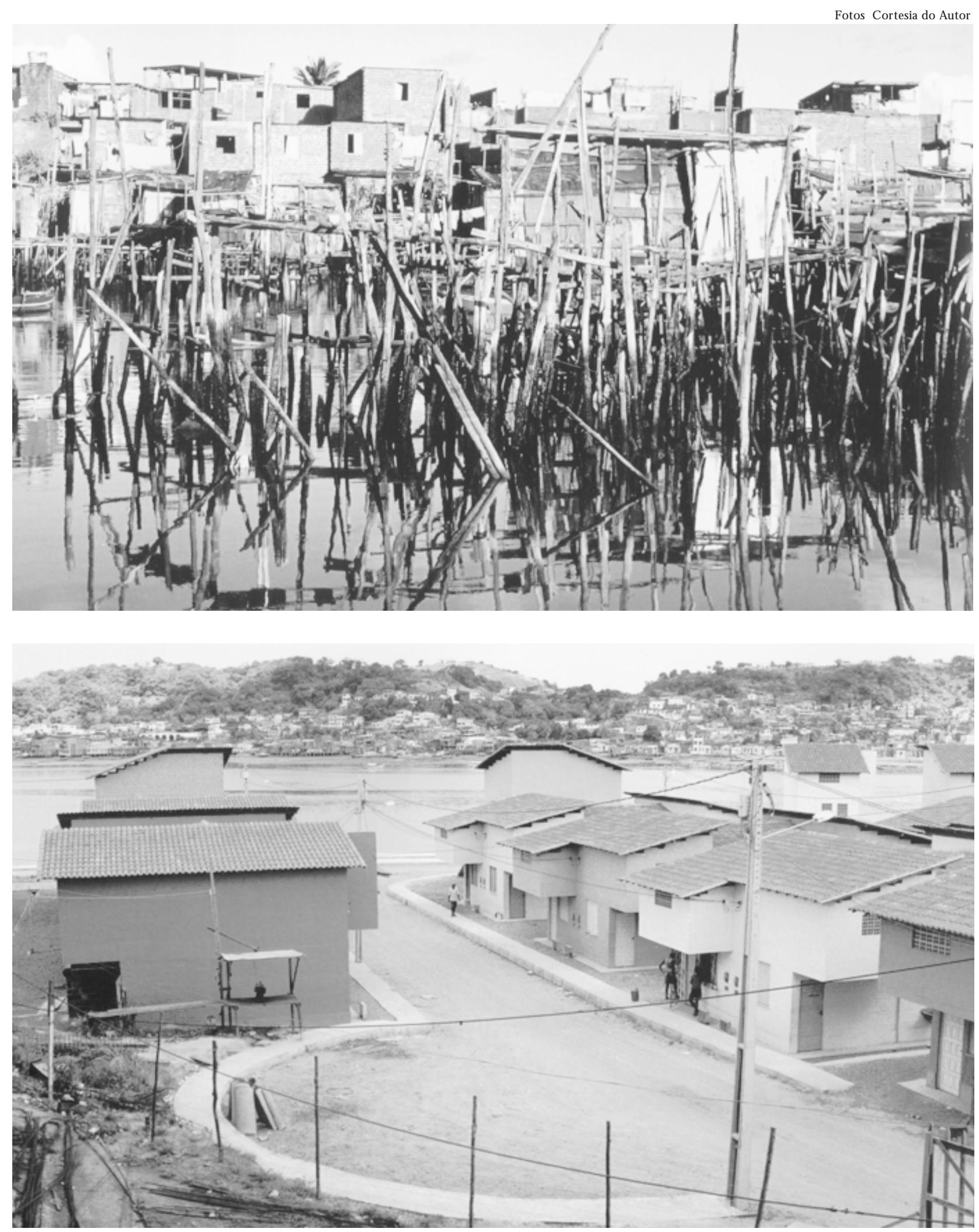

A comparação entre as comunidades de $\mathrm{N}$ ovos A lagados e o reto da área do R ibeira A zul (Salvador-BA )... 

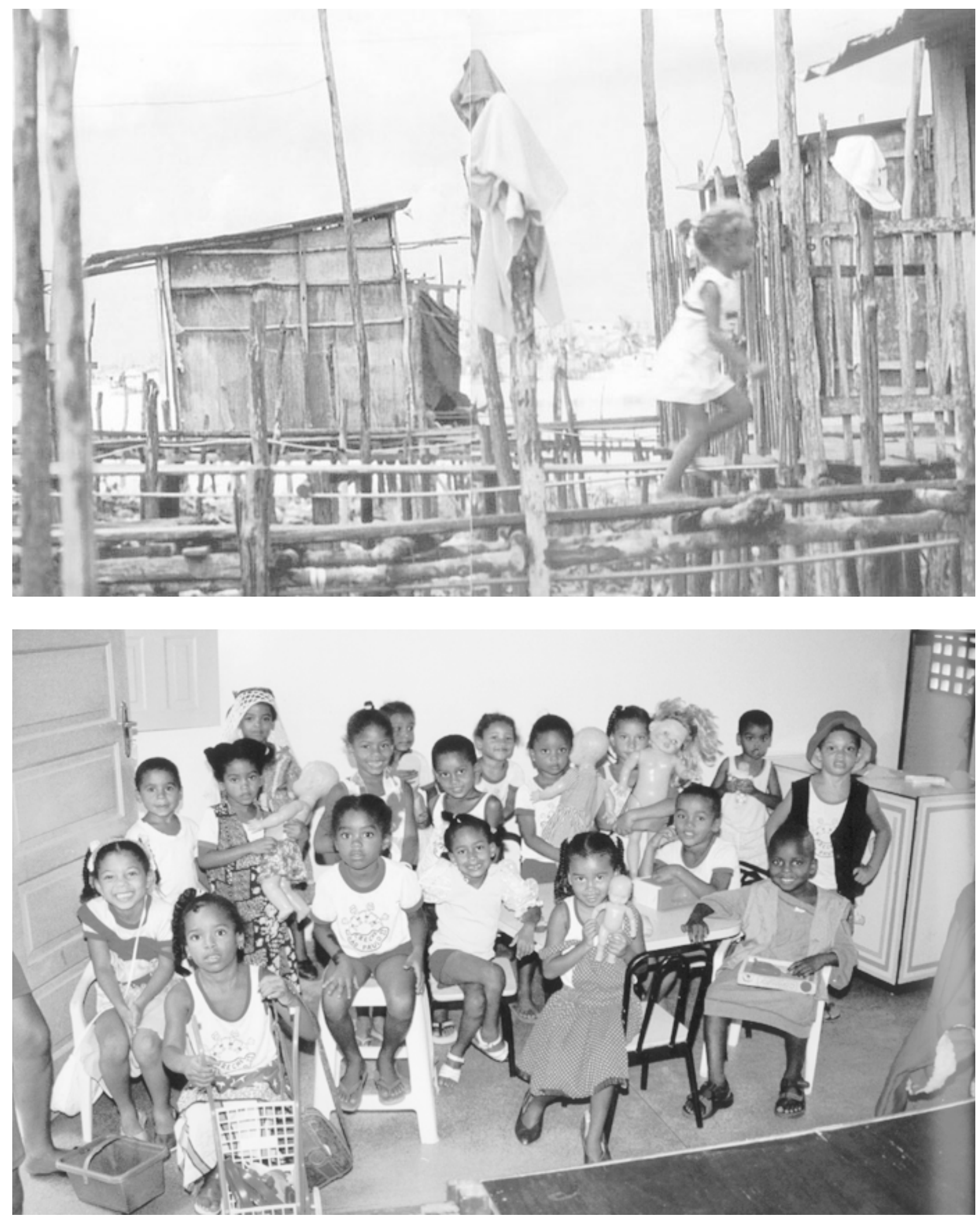

...mostra como um proj eto de urbanização pode efetivamente representar um primeiro passo para o for talecimento da comunidade 
Por outro lado, a noção de crescimento natural, espontâneo, contrapõe-se usualmente à noção de intervenção, de planejamento, de projeto, de controle sobre o processo de produção e ocupação do espaço. [...]

Talvez uma distinção interessante a ser feita seja diferenciar situações nas quais a arquitetura espontânea constitui a regra geral, praticada pelo conjunto da população, de situações nas quais a arquitetura espontânea corresponde à prática de apenas uma parcela da população. N este caso, trata-se, via de regra, da parcela que experimenta diferentes graus de exclusão dos mercados do trabalho, de consumo, de imóveis etc. Assim, quando aparece esta distinção, rompe-se o romantismo ou o idealismo da visão originalmente positiva, passando a prevalecer o conceito de arquitetura espontânea, silenciosa, imposta pela precariedade das condições de vida, ou seja, pela exclusão (C osta Batista, 1998, pp. 263-264).

Portanto, a palavra "silenciosa", mais comumente conhecida como "informal", isto é, que foge às regras estabelecidas para o "desenvolvimento das cidades", assume um aspecto negativo, descreve o retrato de uma situação onde vem à tona a ausência de algo, que ao contrário, a cidade possui.

A tores e mecanismos do crescimento, sistemas de gestão, modalidades através das quais é satisfeita a "demanda de cidade" nos países em desenvolvimento se assemelham sempre mais, seguindo um percurso de homologação que, com a crise dos anos de 1980, se tornou ainda mais visível.

$\mathrm{N}$ a base deste processo de homogeneização está o fato de que, em todos os países, zonas sempre mais amplas das cidades são "ilegais", isto é, fora do previsto no planejamento, nas normas de edificação ou, mais simplesmente, nas regras das propriedades dos solos. Em todos os países, a cidade de "direito" representa só uma parte da cidade construída. 0 resto, é cidade "de fato", aquela construída abusivamente através da ocupação ilegal dos loteamentos; nesses lugares, as casas, na maioria das vezes, são autoconstruídas com materiais precários, achados em qualquer lugar (Balbo, 1992, p. 61).

Informal é, portanto, sinônimo de "não cidade" porque foge às disciplinas de planejamento, às políticas de gestão urbana e às experiências da arquitetura social que se devolveram a partir dos anos de 1940.

N o entanto, a presença da cidade "informal" na estrutura urbana é significativa, para não dizer "imponente" : entre $20 \%$ e $25 \%$ da po pulação de São Paulo, Rio de Janeiro e Belo H orizonte vivem nas favelas, além de $30 \%$ em Salvador, mais de $40 \%$ em Recife. Portanto, sabemos que existe, dela fazemos "experiência cotidiana" , faz parte da realidade urbana que vivemos.

[...] a cidade se constrói na sua totalidade, isto é, todos os seus componentes fazem parte da constituição de um fato. Em outros termos, muito gerais, podemos dizer que a cidade é o progresso da razão humana (enquanto coisa humana por excelência), e essa frase só terá sentido se pusermos em relevo a questão fundamental, isto é, que a cidade e qualquer fato urbano são, por natureza, coletivos (Rossi, 1995, pp. 48-49). 
Este fato assume características específicas nas cidades brasileiras, assim como em todo o território da América L atina.

As cidades dos países em desenvolvimento são compostas por muitos fragmentos que não parecem tender rumo a um crescimento homogêneo, pelo contrário. À medida que essa se expande, este tipo de patchwork espacial se reproduz; no mesmo tempo na cidade que já existe as parte se consolidam sem que se verifiquem significativos processos de integração. [...] Geralmente, cada parte é definida por limites precisos, representados por al guma infra-estrutura como uma estrada de ferro ou uma rua ou por particulares níveis do terreno, mas também por limites de propriedades de uma área. Isto não elimina o fato de que a população com as próprias atividades, às vezes, se assentem nas áreas ricas, nos vazios dos tecidos edificados, construindo casas improvisadas ao lado dos modernos edifícios do centro (Balbo, 1992, pp. 64-65).

As motivações da formação, ao longo do século XX, de um tecido assim fragmentado, são várias e se apresentam de formas diferentes segundo o contexto histórico geográfico. N ão podemos desenvolver nem sumariamente o percurso histórico que gerou tal processo de ocupação do espaço urbano. Remetendo, portanto, à literatura especializada e, em particular, ao livro de N . Bonduki, Origens da habitação social no Brasil, apontamos a seguir as etapas fundamentais desse processo.

Em primeiro lugar, a formação de novas cidades, como no caso de Belo H orizonte e de Brasília levam a um processo de ocupação do território que parte da periferia rumo ao centro planejado e desenhado. Vinte anos após a formação da cidade de Belo $\mathrm{H}$ orizonte, $65 \%$ dos seus habitantes moravam em zonas externas às áreas previstas no projeto.

U m segundo momento da fragmentação, que teve uma ampla repercussão na configuração do território, deu-se com a crise do sistema habitacional nos anos de 1940, a qual, sobretudo em São Paulo, não conseguiu acompanhar 0 crescente êxodo de parte da população rural do Estado para os centros urbanos, principalmente a capital. A conseqüência foi inevitável

Ao contrário do Rio de J aneiro, onde as favelas surgiram no início do sécuIo, em São Paulo elas foram um produto da crise habitacional na década de 1940. Elas significavam uma resistência dos inquilinos em deixar as áreas mais centrais e mudar-se para a periferia. Sem alternativa de moradia compatível com sua renda em local próximo ao emprego, famílias despejadas ou recém-chegadas passaram a ocupar terrenos baldios, onde confeccionavam barracões com madeira e outros materiais improvisados (Bonduki, 1998, pp. 261-262).

0 terceiro momento, o mais recente, acontece entre as décadas de 1960 e 1970, quando a política habitacional é conduzida centralmente pelo Banco Nacional de $\mathrm{H}$ abitação (BNH ). A pesar da grande produção de moradias populares 
nestes vinte anos, o custo das habitações e as suas local izações não permitiram às classes mais pobres adquirir a casa própria. Além disso, nesse processo de recorrer ao déficit com soluções não adequadas, contrariando as experiências anteriores dos IAPs (Institutos de Aposentadoria e Pensões), nos anos de 1940, os arquitetos mais gabaritados ficaram excluídos.

O scar N iemayer, em um artigo publicado na R evista M ódulo de 1979 com o título "U ma cidade para o amanha" chega a conceber uma cidade com

habitações que se distribuiriam em cem grupos com cinco blocos de apartamentos ( 35 andares), num total de oitenta mil habitantes, todos utilizando estes apartamentos, sem distinção de classe ou fortuna, ocupando, cada um, a área que sua família exigisse. Não haveria, portanto, apartamento melhor o pior, nem as antigas casas populares, cujo nome já sugere a discriminação capitalista. [...] Esta é uma opção para a cidade ideal que imagino e que somente o socialismo poderia oferecer. U ma fantasia a que o futuro responderá (N iemayer apud Pereira, 1997, pp. 144).

D essa forma, além de uma prática que não correspondia às necessidades da população pobre, substituiu-se a "experiência da cidade" por uma idéia de cidade. No mundo das idéias a realidade permanece excluída, quando, pelo contrário, deveria ser o ponto inicial do desenvolvimento da resposta.

\section{U rbanização das favelas: o reconhecimento de um fato}

As primeiras tímidas tentativas de resposta, que substituem no final dos anos de 1970 a prática da remoção dos assentamentos informais, nascem do reconhecimento da favela como um dado "de fato" do contexto urbano.

Em M inas Gerais, em 1979, o governo de Estado promove o "Programa de Desenvolvimento Comunitário" (ProDeCom). A pesar do impacto limitado comparado com as necessidades da po pulação, o programa representa o primeiro e evidente sinal de uma mudança de direção. O ProD eC om não nasce claramente do nada: nos mesmos anos, a Conferência N acional dos Bispos do Brasil CN BB, escolheu o "Solo U rbano" como tema da anual Campanha da Fraternidade, com intuito de chamar a atenção para as desigual dades de condição de vida urbana. A través da Campanha, a C N BB ajudava a dar voz aos movimentos populares que tinham como ponto de partida a melhoria das condições dos habitantes das favelas e a necessidade de garantir a sua estabilidade. D essa forma, os movimentos se opunham à prática das remoções que caracterizou a década de 1970. O slogan da "U nião dos Trabalhadores de Periferia" (U TP) de Belo H orizonte, um movimento que reunia os principais líderes comunitário ao redor da Pastoral da Favela, era significativo: "a favela não é um problema, mas uma solução".

A idéia de melhorar as condições físicas dos assentamentos informais se difunde em curto espaço de tempo e o ano 1982 representa um ano decisivo em várias cidades. A lei Pró-Favela em Belo H orizonte, as delimitações específicas e as normas de intervenção em favelas (Zona Especial de Interesse Social), em 
Recife, o início de um programa capilar do de melhoria das infra-estruturas urbanas em D iadema, fazem parte da recente história da habitação po pular no Brasil.

O s resultados dessas experiências, mesmo que iniciais, parecem indicar a estrada a ser percorrida. Concluindo a análise do processo de urbanização nas favelas de D iadema entre os anos de 1983 a 1988, Almeida e Abiko afirmam:

Esses resultados apontam para um:

- alto índice de construção em alvenaria, 3.158 (88,34\%) unidades, assim como de cobertura em laje, 2.716 (75,97\%) unidades;

- tendência à verticalização, já apresentando índice de 45,88\% de unidades sobradadas, todas em alvenaria.

A partir desses dados, é possível afirmar que a urbanização vem de encontro às expectativas da população que, ao se sentir segura no local, investe os recursos de que dispõe na melhoria de seu espaço habitacional. (Abiko e Almeida, 1994).

D esde então, podemos identificar duas gerações de projetos que consolidaram o princípio de recuperação dos assentamentos informais como prática e, sucessivamente, como política de investimento na habitação popular.

$\mathrm{N}$ um primeiro momento, que se concluiu indicativamente que na primeira fase dos anos de 1990, as principais municipalidades do país desenvolveram um programa de melhoria das infra-estruturas por meio de intervenções físicas pontuais. As principais ações se referem às obras de regularização e pavimentação de ruas e vielas, a construção de estradas de acesso às partes mais íngremes das favelas e na construção de muros de contenção nas áreas de risco, a realização do sistema de esgoto mesmo que não oficial por causa da reduzida largura dos becos, além da efetivação das redes de distribuição da água e da energia elétrica. O s investimentos são limitados e de exclusiva competência dos municípios, não são previstos projetos de integração com o contexto urbano, as obras são pontuais e muitas vezes realizadas em "mutirão" 9 .

A partir de 1994 difunde-se uma outra modalidade de intervenção nas principais capitais do país através de programas de al cance municipal e com investimentos significativos, como o "Favela Bairro" no Rio de J aneiro, o "Programa Guarapiranga" em São Paulo, o "Programa Alvorada” em Belo H orizonte e o "Projeto N ovos Alagados" em Salvador. Sucessivamente, estas experiências foram incorporadas em um amplo Programa $\mathrm{N}$ acional chamado $\mathrm{H}$ abitar-Bid, que se tornou o principal instrumento da Secretaria de Política U rbana, hoje transformada em M inistério da Cidade.

O fio condutor de toda essas experiências é a conscientização, desde os primeiros programas de urbanização, de que a favela representa um fato urbano consolidado e, portanto, um patrimônio habitacional que deve ser recuperado e desenvolvido. Coloca-se, portanto, ênfase nos aspectos do projeto urbanístico visando a melhorar os padrões qualitativos e as características morfológicas dos assentamentos; o projeto integrado da área substituiu os projetos pontuais das 
intervenções da primeira geração, definindo métodos e instrumentos de projetos e gestão das informações ${ }^{10}$.

$\mathrm{O}$ programa $\mathrm{H}$ abitar-Bid reafirma essa lógica de projeto ampliando-a para todas as cidades interessad as e colocando dois requisitos fundamentais para apresentação do projeto: a demonstração de uma efetiva capacidade institucional da municipalidade de enfrentar o problema dos assentamentos informações e de desenvolver a intervenção proposta e a definição de critérios de seleção e prioridade na escolha da área proposta.

\section{U ma concepção diferente da pobreza: um patrimônio adormecido}

A mudança de mentalidade gerada pelo reconhecimento das favelas como parte integrante das cidades, a superação entre a cidade formal e a informal, 0 reconhecimento da "cidade real", isto é, constituídas por todas as suas partes, tem como primeiro resultado a afirmação "do direito de morar". O novo Estatuto da Cidade confirma de forma clara esse percurso, cuja experimentação prática é representada pelos programas de urbanização desenvolvidos nesses 25 anos.

$M$ as, mesmo que tal processo representasse o desenvolvimento de um modelo inclusivo, ao longo desses anos não houve um nexo real entre as concepções de pobreza, apresentadas no começo desse documento e as formas de urbanização até hoje desenvolvidas. As experiências de redução da pobreza assumiram, de um lado, o aspecto emergencial na tentativa de reduzir o percentual da população pobre, por outro lado, representaram intervenções setoriais voltadas para a meIhoria dos indicadores de base do desenvolvimento, como a redução da taxa de analfabetismo, a redução da mortalidade infantil e o aumento da freqüência escolar. Porém, quase todas essas experiências foram desenvolvidas sem o enfoque territorial. D e fato, essa mesma definição regional das prioridades representa uma leitura estatística da concentração do problema. Por outro lado, vimos como programas de urbanização foram direcionados rumo ao upgrading físico-ambiental, na tentativa de melhorar as condições de moradia dos assentamentos. Raramente existem casos de real integração dos investimentos; certamente não existe uma política estrutural de redução da pobreza que inclua o desenvolvimento integrado de todas as potencialidades das comunidades pobres.

M esmo que o Programa $\mathrm{H}$ bitar-Bid introduza alguns elementos de desenvolvimento socioeconômico, as ações e os investimentos previstos neste âmbito não são comparáveis com os investimentos nas infra-estruturas financiados pelo mesmo programa. D essa forma, corre-se o risco de favorecer um desenvolvimento não sustentável (contrariamente às necessidades do país) porque não se favorece um crescimento equilibrado das potencialidades das comunidades.

Se voltarmos a examinar com maior atenção as motivações que sustentaram os primeiros programas de intervenção nas favelas, podemos descobrir um elemento que introduz uma diferente percepção do problema da pobreza e, con- 
seqüentemente, um princípio de projeto de fundamental importância: o reconhecimento não só da existência do problema, mas também das tentativas de solução que as pessoas construíram para responder as necessidades cotidianas. Por exemplo, a lei Pro-Favela de Belo H orizonte afirma que: "O Setor Especial destina-se à urbanização específica de favelas e deverá observar, tanto quanto possível, as características da ocupação espontânea". E m outras palavras, são reconhecidas as tentativas de resposta, mesmo que inadequadas e que, portanto, necessitam de significativas intervenções corretivas.

A seu modo, as famílias pobres, sozinhas e com poucos recursos, organizaram uma resposta às próprias necessidades. D a maneira que podiam, elas, colocar à disposição o conjunto de "bens" que possuíam para melhorar as suas condições de vida; vale ressaltar que, geralmente, boa parte destes recursos não são diretamente classificados dentro de uma avaliação monetária. Por exemplo, o núcleo familiar e os relacionamentos com amigos e com a vizinhança são elementos normalmente usados como forma de responder ao problema. Em muitos casos, as pessoas que vivem em situação de pobreza colocam inteligentemente à disposição os talentos que possuem. Assim, muitas vezes, não foi possível desenvolver melhor estas capacidades e responsabilidades diante da realidade porque as circunstâncias assim não propiciaram. Portanto, o pobreéaquela pessoa que não tem possi bili dadededesenvol ver ostalentosquerecebeu, isto é, não possui o a cesso às reais oportunidades que Ihe permitiriam desenvolver todas as próprias potencialidades. Pode-se, assim, ser dignamente pobre e jogar com todas as possibilidades humanas que se tem para tentar responder à realidade.

Então, a dignidade da pessoa e o seu desenvolvimento humano são a finalidade última de cada tipo de intervenção.

0 desenvolvimento humano de um povo não deriva primeiramente nem do dinheiro, nem da ajuda material, nem das estruturas técnicas e sim do amadurecimento da mentalidade e dos costumes. É o homem o protagonista do desenvolvimento, não o dinheiro ou a técnica (J oão Paulo II, 1990).

É a pessoa, de fato, o motor do desenvolvimento, o fator indispensável de o todo desenvolvimento possível: a pessoa com as suas necessidades, que freqüentemente se apresentam de maneira parcial e imediata, mas também mostrando to da a sua potencial idade, os seus desejos mais profundos, as suas tentativas de respostas e os seus dramas já vividos.

C ada pessoa, cada comunidade, por mais carente que seja, representa uma riqueza e demonstra um grande valor. Para ajudar a desenvolver os próprios talentos e a mover a responsabilidade pessoal, é necessário valorizar e reforçar aquilo que as pesso as já construíram, a pró pria história, as relações existentes, isto é, reafirmar aquele tecido social e aquele conjunto de experiências que constitui o seu patrimônio de vida. É um ponto operativo fundamental que nasce de uma abordagem positiva da realidade e que ajuda a pessoa a entender o seu próprio valor, a sua dignidade e, desse modo, a desenvolver uma responsabilidade. 
A respeito do estudo comparativo realizado pelo Banco $M$ undial sobre a modalidade com a qual quatro comunidades pobres, em quatro diferentes continentes, reagiram à crise econômica dos anos de 1980, a socióloga C aroline M oser (1996) conclui que, na análise de uma comunidade

é importante identificar não somente as ameaças, mas também aquelas capacidades de adaptação, de aproveitar as oportunidades e de resistir aos efeitos negativos das mudanças do ambiente externo. O s meios para resistir são os recursos que os indivíduos, as famílias e as comunidades podem colocar em campo para enfrentarem as necessidades. Portanto, a vulnerabilidade é estritamente vinculada à posse de recursos. Q uanto maior são os bens e quanto maior é a corrosão deles, tanto maior é a insegurança (p. 2).

Se estendermos a observação de Caroline M oser (1996) não somente com base nos bens materiais ${ }^{11}$, mas também se considerarmos o homem na sua incansável busca de significado, que o torna capaz de colocar em ação todas as potencialidades e talentos que possui, as considerações finais não mudam, aliás, assumem uma configuração ainda mais completa.

Se considerarmos como "patrimônio" o conjunto de recursos palpáveis e impal páveis que as pessoas possuem pode-se concluir que:

$$
P=f(1 / V)
$$

0 patrimônio $(P)$ é inversamente proporcional à situação de vulnerabilidade (V) das comunidades pobres. Assim, para reduzir a vulnerabilidade é necessário reforçar os recursos dos quais a comunidade pode dispor para enfrentar as situações críticas.

\section{D iminuir a pobreza e fortalecer o patrimônio: o exemplo do Ribeira Azul}

Este ponto de partida carrega consigo uma forma operativa diferente daquelas até agora apresentadas. Para descrever melhor o possível desenvolvimento operativo dessa concepção apresentamos, mesmo que sumariamente, um projeto de redução da pobreza em andamento em Salvador: o "Programa Ribeira Azul".

A área do "Programa Ribeira Azul" é o trecho ao longo da orla marítima da Baía de Todos os Santos, compreendido entre a Praia da Penha e São J oão de Plataforma, no subúrbio ferroviário de Salvador, ocupando uma área de $4 \mathrm{Km}$, constituída pelas comunidades de Alagados Antigos, Península do J oanes e N ovos Alagados. $6 \%$ da po pulação do M unicípio de Salvador reside na região, sendo 133.387 pessoas.

N esta área de Salvador, que é considerada uma daquelas com maior nível de degradação urbana e ambiental, mora cerca 33 mil famílias das quais mais de três mil vivem em palafitas ocupando a baía; há uma grande concentração de vulnerabilidades sociais, como o baixo nível de escolaridade, desemprego, informalidade no trabalho, proliferação de doenças infecto-contagiosas, situação epidemio- 
lógica de alto risco, e elevados índices de violência, caracterizando-se como um sistema urbano muito diferenciado da cidade formal. Aqui se concentra $15 \%$ da população pobre da cidade, que vive, portanto, com uma renda inferior à linha da pobreza.

A metodologia de intervenção aplicada foi primeiramente aplicada em uma área menor, onde vivem cerca de duas mil famílias, conhecida como N ovos Alagados e, neste programa, foi adaptada a fim de promover a passagem de escala.

Como em qualquer projeto abordando o problema da pobreza da área do Ribeira Azul, respeitamos as etapas clássicas do "ciclo de projeto", reconhecendo a situação inicial, definindo ações de melhoria da qualidade de vida para, então, sucessivamente, realizá-las ${ }^{12}$.

Reequilibrar o patrimônio foi o objetivo principal do Projeto N ovos Alagados, assim como hoje representa o fim da intervenção do Ribeira Azul.

Podemos, de fato, afirmar que um programa de redução da pobreza deve, como objetivo principal, contribuir para aumentar o patrimônio das famílias e da comunidade. M esmo uma ação setorial, pensada e desenhada para reduzir ou eliminar uma situação específica de risco, pode contribuir para a melhoria do patrimônio. 0 objetivo de uma ação para reduzir a pobreza pode ser sintetizado na seguinte formulação:

$$
\Delta \mathrm{P}=\mathrm{Po} \times \mathrm{I}
$$

A variação do patrimônio $(\Delta \mathrm{P})$ é dada pela real incidência da ação de projeto (I), qualquer que seja, sobre o patrimônio inicial (Po) daquela determinada comunidade. U ma ação positiva em si pode, de verdade, não produzir o impacto esperado. Somente quando a pessoa está capacitada para colher a oportunidade, isto é, quando o agir incide sobre o patrimônio inicial colocando-o em movimento de maneira estável, é possível criar condições para reduzir a vulnerabilidade dentro das famílias e das comunidades. U m curso de formação profissional que não considere o impacto que o contexto socioeconômico e familiar gera nos jovens e nas suas identidades não forma alunos para enfrentarem efetivamente 0 mundo do trabalho; é necessário investir na formação humana destes estudantes e recuperar primeiramente os elementos que ajudam a recolocar o significado do trabal ho para a vida deles. D e modo geral, a ação deve levar em consideração os recursos existentes (e deve ser, portanto, adequada na sua formulação metodológica e nos seus prazos de realização) para garantir um real incremento do patrimônio na comunidade. U m sujeito externo (público, privado ou da sociedade civil) que queira contribuir com o desenvolvimento da comunidade por meio de uma ação de qualquer natureza (seja esta de melhoria urbana, de construção da rede de energia elétrica, de fomento da produção de renda) não pode "substituir-se" a comunidade beneficiada, mas deve desenvolver ações de suporte. A busca dos "fatores positivos", dos "multiplicadores de desenvolvimento", dos "corpos intermediários" eficazes que podem representar um valor agregado 
à ação específica, deve ser objeto da nossa preocupação desde o momento inicial do projeto.

Por estas razões, na análise da situação inicial, consideramos os vários aspetos da vida das pessoas: foram coletados dados censitários e amostrais que colocassem em evidência não somente os aspectos físicos, mas também as outras dimensões do patrimônio das famílias - moradia, trabalho educação, saúde, relações familiares, laços de solidariedade. O s dados coletados na primeira fase do projeto foram representados por meio de mapas temáticos e gráficos que constituem 0 conjunto dos "R etratos das Comunidades" do Ribeira Azul. D essa forma, temos um quadro completo das necessidades e da situação de vulnerabilidade dos grupos presentes. Sucessivamente, os mesmos dados foram analisados através de regressões lineares e de coeficientes de cograduação (coeficiente de Kendal) para entender as relações internas entre os componentes do patrimônio. É possível, assim, identificar os fatores que influenciam positivamente o nível de desenvolvimento no específico contexto social e territorial. Por exemplo, é possível entender que existe uma relação estreita e diretamente proporcional entre "qualidade da casa" e "escolaridade juvenil feminina", entre "ocupação adulta feminina" e "escolaridade juvenil feminina", entre "nível de saúde dos adultos" e "nível de saúde infantil" etc. Esse patrimônio deve ser colocado em ação; realizar ações que favoreçam o seu desenvolvimento é sinônimo de estimular as responsabilidades das pessoas e dos grupos familiares.

U ma forma substancial para alcançar os objetivos é aquela que desenvolve as agremiações espontâneas e as organizações. $\mathrm{N}$ ão existe comunidade na qual não se encontrem grupos mais ou menos constituídos, dentro de ela própria ou fora, que prestam serviços de várias naturezas às pessoas e às famílias. E stes também representam um recurso importante para o desenvolvimento da sociedade; eles nascem, de fato, da livre agregação de pessoas e de famílias. Agir em favor do desenvolvimento social significa também favorecer as capacidades de associação das pessoas e grupos, ou seja, reconhecer, valorizar e estimular o constituir-se de comunidades intermediárias e de um tecido social ricos de participação e de coresponsabilidade. 0 direito de toda pessoa à liberdade de associação e de empreendimento, até mesmo o econômico, revela-se, na experiência, uma força potente de mudança.

N os programas de desenvolvimento é fundamental realizar uma parceria entre tais sujeitos e as entidades envolvidas, colocando em movimento sinergias e significativas quantidades de recursos. Trata-se de partir de um sujeito existente, que envolve nas ações as administrações locais, as forças so ciais, as instituições internacionais, numa ação comum, segundo respectivas funções, para responder às necessidades.

A comparação entre as comunidades de $\mathrm{N}$ ovos Alagados e o resto da área do Ribeira Azul mostra como um projeto de urbanização pode efetivamente representar um primeiro passo para o fortalecimento da comunidade, se se con- 
sideram todos os fatores existentes. Tendo como ponto de partida uma situação certamente pior em termos da qualidade de serviços ( $a$ área de $\mathrm{N}$ ovos Alagados apresenta-se menos consolidada e mais longe do centro urbano), o projeto de urbanização direcionou o próprio esforço para a melhoria física-ambiental da área, bem como no fortalecimento das iniciativas, de qualquer natureza, capazes de fornecer efetivos serviços à comunidade.

A pesquisa sobre os "corpos intermediários" presentes na área do Ribeira Azul, também realizada na fase inicial do programa, mostrou, por diferença, 0 êxito do precedente projeto de N ovos Alagados.

Entre os noventa projetos desenvolvidos pelas 67 entidades que responderam ao questionário, 26 se localizam na área de $\mathrm{N}$ ovos Alagados, onde vivem pouco mais de 21 mil pessoas quando outros sessenta projetos concentram-se na área mais consolidada de Alagados Antigos, onde vivem mais de 91 mil pessoas. O s serviços comunitários na área de N ovos Alagados atendem a 17\% da população, quando na área mais próxima à cidade atendem apenas $6 \%$ da po pulação.

\begin{tabular}{|l|c|c|c|c|}
\hline \multicolumn{1}{|c|}{ Setor } & $\begin{array}{c}\text { Setor 1 } \\
\text { (Novos } \\
\text { Alagados) }\end{array}$ & $\begin{array}{c}\text { Setor 2 } \\
\text { (Área } \\
\text { Intermediária) }\end{array}$ & $\begin{array}{c}\text { Setor 3 } \\
\text { (Alagados } \\
\text { Antigo) }\end{array}$ & Total \\
\hline Total de Projetos & 26 & 4 & 60 & 90 \\
\hline $\begin{array}{l}\text { População Total } \\
\text { Estimada }\end{array}$ & 21.248 & 20.650 & 91.489 & 133.387 \\
\hline $\begin{array}{l}\text { № de Projetos para } \\
\text { cada mil pessoas }\end{array}$ & 1,23 & 0,2 & 0,66 & 0,67 \\
\hline
\end{tabular}

\begin{tabular}{|c|c|c|c|c|c|c|c|c|c|c|c|}
\hline \multirow[b]{2}{*}{ Setor } & \multirow[b]{2}{*}{$\begin{array}{l}0 \\
\frac{0}{0} \\
\frac{0}{0} \\
\frac{0}{0} \\
0 \\
0 \\
01 \\
z\end{array}$} & \multirow[b]{2}{*}{$\circ$} & \multicolumn{8}{|c|}{ Área Temática } & \multirow[b]{2}{*}{ 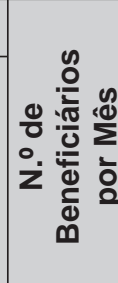 } \\
\hline & & & $\begin{array}{l}\frac{\pi}{\pi} \\
\frac{\pi}{0} \\
\frac{\pi}{1} \\
\end{array}$ & 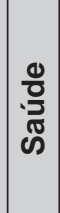 & 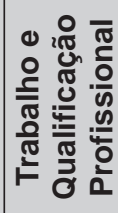 & 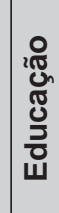 & 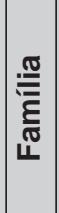 & 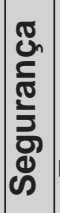 & 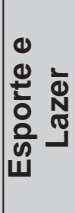 & 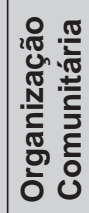 & \\
\hline Setor 1 (Novos Alagados) & 26 & $28,89 \%$ & 3 & 15 & 9 & 18 & 15 & 3 & 12 & 18 & 3.631 \\
\hline Setor 2 (Área Intermediária) & 4 & $4,44 \%$ & 1 & 2 & 2 & 2 & 2 & & 1 & 2 & 736 \\
\hline Setor 3 (Alagados Antigo) & 60 & $66,67 \%$ & 18 & 30 & 29 & 50 & 41 & 3 & 36 & 20 & 5.657 \\
\hline Total & 90 & $100,00 \%$ & 22 & 47 & 40 & 70 & 58 & 6 & 49 & 40 & 10.024 \\
\hline
\end{tabular}

M ais da metade das instituições que fornecem serviços na área de $\mathrm{N}$ ovos Alagados tem mais de dez funcionários, operam numa sede própria ou alugada e assinam convênios com entidades mantenedoras ou com o poder publico; $60 \%$ delas preocupam-se com a formação dos próprios funcionários. Começou assim o caminho rumo à estabilidade e à qualidade dos serviços. 
D eve ser esta a razão de um dado atípico. No começo do Projeto N ovos Alagados houve a necessidade de se realocar em casas novas, construídas numa área livre situada na mesma comunidade, mais trezentas famílias que viviam em palafita. $\mathrm{H}$ oje, após cinco anos, apenas 3\% dessas famílias não residem mais na mesma comunidade. 0 dado, se comparado com os valo res médios dos processos de realocação involuntária, que indicam uma taxa de abandono superior aos $20 \%$ dasfamílias, é significativo. A grande maioria das famílias reconheceu que a melhoria global da qualidade de vida do assentamento representa um bem superior, respeito à disponibilidade de liquidez imediata que a venda da casa pode produzir.

As experiências de programas de redução da pobreza representam somente o início de um longo caminho de desenvolvimento. É o momento de experimentar méto dos e formas de intervenção, em vez de se recorrer a sonhos de uma mágica e repentina redução das diferenças regionais e das desigualdades estruturais: por isso, um processo cuidadoso de monitoramento das experiências mais importantes pode representar a melhor forma de se construir programas e políticas sustentáveis.

N otas

1 U ma atenta descrição do processo cognitivo no âmbito dos programas de redução da pobreza pode ser encontrada em G. M. B. Solymos, "Vencendo a desnutrição: abordagem psicológica", São Paulo, Salus Paulista, 2002, pp. 17-25. 0 texto faz parte da coleção "Vencendo a desnutrição", de Gisela M. B. Solymos e de A. L. Sawaya, publicado com o apoio do Banco N acional de D esenvolvimento Econômico e Social (BN DES) com o objetivo de divulgar os instrumentos úteis para uma política pública de redução da desnutrição. Os textos daquela coleção são publicados no site www. desnutricao.com.br .

20 texto apresenta um percurso completo dos estudos de natureza econômica dos últimos anos sobre o fenômeno da pobreza no Brasil e de análise das principais tentativas de redução do fenômeno através das políticas e de programas públicos.

3 "O s resultados revelam que, em 1999, cerca de 14\% da população brasileira vivia em famílias com a renda inferior à linha de indigência e 34\% em famílias com renda inferior à linha de pobreza. D este modo, cerca de 22 milhões de brasileiros podem ser classificados como indigentes e 53 milhões como pobres" (Barros et al., 2000 (a), p. 23).

4 Em 2001 o Brasil estava classificado no 69ㅇ lugar.

5 Para uma apresentação das modalidades de cálculo do índice de Vulnerabilidade Social elaborado pela Prefeitura de Belo H orizonte em Colaboração com a Pontifícia U niversidade Católica de $\mathrm{M}$ inas G erais ver: PBH : Planejar BH , M apa de exclu são social. Belo H orizonte, n. 8, ago. 2000.

6 U ma apresentação do programa se encontra em Ferreira e Amaral, 2001.

7 Entendemos por "serviços de utilidade pública" o conjunto dos serviços ofertados à pessoa seja no setor público como no setor no profit. 
8 Para os curiosos, ver a propósito deste tema em G ori e Vittadini, 1999.

$9 \mathrm{U} \mathrm{m}$ documento que descreve bem as características das intervenções e o manual publicado pelo Governo do Estado de M inas Gerais com a colaboração da GTZ ml 1992: M elhorias U rbanas em Vilas e Favelas - O rientações técnicas.

10 A publicação editada pelo U N CH S ( $\mathrm{H}$ abitat): Putting the U rban Poor on the Map descreve detal hadamente os passos metodológicos dessa segunda geração de projeto e apresenta os instrumentos informáticos de gestão das informações que em alguns casos foram usados.

11 Sobre o conceito de "recursos" ver também N eri em H enriques, 2000, pp. 509-517.

12 O s passos operativos de um programa de redução de pobreza são apresentados em Gatti e N ovara em M affenini, 2003, p. 14.

\section{Bibliografia}

ABIKO, A. K. e ALM EIDA, M . A. P. U rbanização defavelasem Diadema no período de 1983 a 1988. São Paulo, BT/ PCC/ 128-U SP, 1994.

AGU IAR, M. eARAÚ J O , C. H . Bolsa-escola: educação para enfrentar a pobreza. Brasília, U nesco, 2002, p. 32.

BALBO, M. Povera Grande Città. M ilano, Franco Angeli, 1992.

BARROS, R. Paes de et al. (a). "A estabilidade inaceitável: desigualdade e pobreza no Brasil”. Em H EN RIQ U ES, R. D es gualdadee pobreza no Brasil. Rio de J aneiro, I pea, 2000, pp. 22-37.

(b). Pobreza epolítica social. São Paulo, Fundação Konrad Adenauer, 2000.

BONDUKI, N. Origens da habitação social no Brasil. São Paulo, Estação Liberdade/ Fapesp, 1998.

FERREIRA, A. L.; VELOSO, C. e AMARAL, T. do. "BH Cidadania: o percurso da política social". Em Pensar BH - Política Social. Belo H orizonte, 2001.

GATTI, M . T. "The Role of N on-Governmental O rganizations". Em M AFFEN I NI, W. Partnership Experiences A gainst U rban Poverty. M ilano, Franco Angeli, 2003, pp. 8385.

GATTI, M. T. e N OVARA, E. "The Real City. M ethods and Actions I mplemented by AVSI to U pgrade I nformal U rban Areas". Em M AFFE N I I I, W. Partnership Experiences A gainst U rban Poverty. M ilano, Franco Angeli, 2003, pp. 14-21.

GIACOMINI, M. R.; H AYASH I; M . ePIN H EIRO, S. A. "O trabalho social em favela: o método da condivisão". Em SO L YM OS, G . M . B. Coleção vencendo a desnutrição: abordagem psicológica. São Paulo, Salus Paulista, 2002, p. 20.

GORI, E. eVITTADINI, G. Qualità eValutazionené Servizi di Pubblica U tilità. M ilano, Etas, 1999.

GIU SSAN I, L. O senso religioso. Rio de Janeiro, N ova Fronteira, 2000.

JOAO PAU LO II. RedemptorisM issio, n. 58-59, 7 dez.1990.

LAVIN AS, L. "Programa de garantia de renda mínima e ação coordenada de combate à pobreza". Em AGU IAR, M . e ARAÚ J O C. H . Bolsa-escola: educação para enfrentar a pobreza. Brasília, U nesco, 2002. 
M OSER, Caroline O. N . SituacionesC riticas. R eacción delasFamiliasdeC uatro C omunidades U rbanas Pobresante de la Vulnerabilidad y de la Pobreza. Washington D.C., Banco M undial, 1996.

NERI, M. "Políticas estruturais de combate à pobreza no Brasil". Em HEN RIQUES, R. D es gualdade e pobreza no Brasil. Rio de Janeiro, I pea, 2000, pp. 509-517.

N O VARA, E. "The role of Civil Society". Em M AFFE N I N I, W. Partnership Experiences A gainst U rban Poverty. M ilano, Franco Angeli, 2003, pp. 77-82.

PBH : Planejar BH - Mapa deExclusão Social. Belo H orizonte, n. 8, ago. 2000.

PEREIRA, M. A. A rquitetura, texto e contexto: o discurso de Oscar N iemeyer. Brasília, Editora da U nB, 1997.

PIO XI, Papa. Enciclica Q uadragesimo Anno, 15 maio 1931.

PO CH M AN N , M . e AM ORIM , R. A tlasdeexclusão social no Brasil. São Paulo, Cortez, 2003.

ROSSI, A. A arquitetura da cidade. São Paulo, M artins Fontes, 1995.

SI LVA, J I I. Rosas. Guia dereassentamento involuntário depopulação urbana deinteresse social. Programa Soma, Belo H orizonte, 1999.

SO ARES, M . C. H . e BAPTISTA, M . E. "Arquitetura silenciosa”. Em CAST RI OTA, L. B. A rquitetura de modernidade. Belo H orizonte, Editora da U FM G, 1998.

SO L YM O S, G . M . B. C oleção Vencendo a desnutri ção: abordagem psicológi ca. São Paulo, Salus Paulista, 2002.

U N CHS (H abitat). Putting the U rban Poor on the Map: A n Informal Settlement U pgrading M ethodologySuppor ted by I nformation Technology. N airoby, U N CH S, 2000.

U N CH S (H abitat). "Pobreza: um desafio mundial". D ed aração do R ecife, Recife, 1996.

"U RBEL :U rbanização de favelas e prevenção em áreas de risco em Belo H orizonte". Em BO N D U KI, N . H abitat: as práticas bem sucedidas em habi tação, mei o-ambi entee gestão urbana nascidades brasileiras. São Paulo, Studio N obel, 1996, pp.152-155.

VIL LAÇA, F. Espaço intra-urbano no Brasil. São Paulo, Studio N obel, 1998.

R ESU Mo - A DIM EN SÃo da pobreza, a sua distribuição regional, as diferenças do fenômeno na área rural e na cidade, são elementos de conhecimento público. A cidade brasileira mostra cotidianamente as feridas causadas pela desigual distribuição de renda e pela exclusão social: a configuração espacial do território intra-urbano é o mais nítido retrato do fenômeno, que hoje representa o principal obstáculo ao desenvolvimento sustentável do país. A pesar desta evidência, os programas de redução da pobreza, desenvolvidos nos últimos anos, apresentam poucos pontos de integração com a realidade territorial. Por outro lado, a desigual distribuição de renda e a exclusão social de ampla parte da população, mesmo descrevendo detalhadamente o problema, não ajudam a identificar os pontos de partida e os elementos positivos que devem ser fortalecidos para implementar programas integrados de redução da pobreza.

A história e as experiências de programas de urbanização dos últimos 25 anos podem contribuir para definir um percurso metodológico a partir das potencialidades, mesmo que adormecidas, das pessoas que vivem a situação de pobreza. 
Chamamos "patrimônio" o conjunto de recursos pal páveis e impal páveis que as pessoas possuem e podem colocar em jogo para enfrentar as situações críticas que estão vivendo. I dentificar e desenvolver ações que possam aumentar este patrimônio, reduzindo a vulnerabilidade das famílias, pode ser o caminho a ser percorrido. 0 desenvolvimento de "corpos intermediários" e de atores intermediários capazes de compartilhar necessidades e potencialidades representa uma etapa fundamental deste percurso.

A BStRACt - THE DIMENSION of poverty, its regional distribution, the differences of the phenomenon in the rural area and in the city, are widely known elements. The Brazilian city shows, on a daily basis, the wounds caused by the unequal distribution of income and social exclusion: the spatial configuration of the urban territory is the clearest portrait of the phenomenon, representing the main obstacle for the country's sustained development. D espite this evidence, poverty reduction programs present few points of integration with the territorial reality. O $\mathrm{n}$ the other hand, the unequal distribution of income and social exclusion of considerable part of the population, even if describing poverty in detail, do not help in identifying the points of departure and the positive elements which should be strengthened for the implementation of poverty reduction programs. The history and experiences of the projects for the urbanization of the favelas of the last twenty five years may contribute to define a methodological path starting from the potentialities, even if dormant, of the persons who live the reality of poverty. We call "patrimony" the set of palpable and impalpable resources possessed by these persons and that can be used to face the critical situations in which they live. The path to be taken may be the identification and development of actions to increase these patrimonies, reducing the vulnerability of the families. The development of "intermediary organisms" and of social agents, able of sharing the necessities and potentialities, represent a fundamental stage in this path.

Enrico $\mathrm{N}$ ovara é formado em Engenheria Civil pelo Politecnico de $\mathrm{M}$ ilano, tem especialização em Engenheria A mbiental pelo Politecnico de M ilano e em G estão de D esenvolvimento L ocal pelo O IT (O rganização I nternacional do Trabalho). D esde 1994 é country representative de AVSI (Associazione Volontari per il Servizio Internazionale), ONG internacional com sede na I tália que opera em trinta países. É coordenador de vários projetos de desenvolvimento urbano e redução da pobreza, entre os quais o Programa Alvorada (Belo H orizonte) e o Projeto N ovos Alagados (Salvador), os quais foram escoIhidos como best prectises na C onferência I nternacional $\mathrm{H}$ abitat II, em I stambul.

Texto recebido e aceito para publicação em 9 de junho de 2003. 